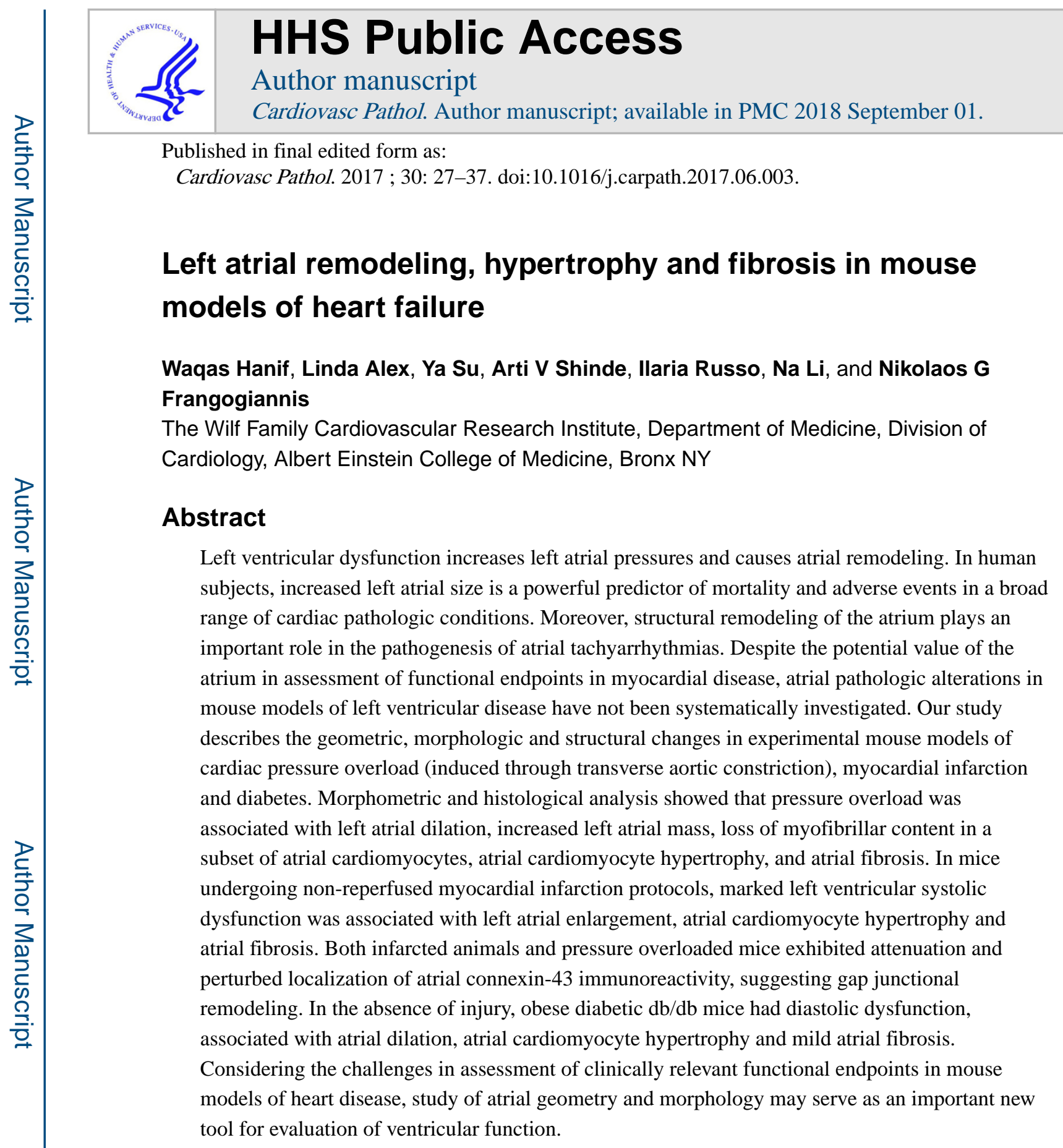

\title{
Keywords
}

myocardial infarction; heart failure; atrial remodeling; fibrosis; hypertrophy; diabetes

\footnotetext{
Address for correspondence and reprint requests: Nikolaos G Frangogiannis, Division of Cardiology, the Wilf Cardiovascular Research Institute, 1300 Morris Park Avenue Forchheimer G46B, Albert Einstein College of Medicine, Bronx NY 10461, Tel: 718-430-3546, Fax: 718-430-8989, nikolaos.frangogiannis@einstein.yu.edu.

Publisher's Disclaimer: This is a PDF file of an unedited manuscript that has been accepted for publication. As a service to our customers we are providing this early version of the manuscript. The manuscript will undergo copyediting, typesetting, and review of the resulting proof before it is published in its final citable form. Please note that during the production process errors may be discovered which could affect the content, and all legal disclaimers that apply to the journal pertain.

DISCLOSURES: None.

CONFLICTS OF INTEREST: None
} 


\subsection{INTRODUCTION}

Perturbations in left ventricular function have profound effects on the geometry and structural properties of the left atrium. Both systolic and diastolic heart failure result in elevation of left atrial pressures, leading to atrial dilation and hypertrophy. In human subjects, adverse left atrial remodeling predicts mortality and adverse outcome in a wide range of cardiac pathologic conditions. In a cross-sectional sample of a population $>45$ years of age, increased atrial volume was a marker of severity and duration of diastolic dysfunction (1). In patients surviving acute myocardial infarction, left atrial volume was found to be a powerful predictor of mortality (2), and provided incremental prognostic information over clinical and echocardiographic data (3). Left atrial volume independently predicted adverse outcome in patients with hypertrophic cardiomyopathy (4), ischemic cardiomyopathy (5), and chronic heart failure (6). The prognostic value of atrial size is not limited to patients with established myocardial disease, but has been extended to individuals free of cardiovascular conditions. In subjects with type 2 diabetes, but without any known cardiovascular disease, left atrial volume was found to be an independent predictor of morbidity and mortality (7). In a population of middle aged and elderly individuals free of clinical cardiovascular disease, left atrial diameter was an independent predictor of incident first cardiovascular events (8). Thus, in human patients, assessment of left atrial size and geometry is a valuable tool in evaluation of ventricular function and provides important prognostic information.

In addition to its prognostic significance, remodeling of the left atrium plays an important direct role in the pathogenesis of atrial tachyarrhythmias (9). Atrial fibrosis disrupts electrical conduction and predisposes to initiation and maintenance of atrial fibrillation (10), (11),(12). Moreover, structural and geometric atrial remodeling generates a thrombogenic substrate that predisposes to ischemic stroke and systemic embolic events (13).

Mouse models of myocardial disease have been extensively used to study the pathophysiology of myocardial infarction and heart failure (14),(15),(16),(17),(18),(19),(20). Although sophisticated imaging modalities, histopathologic studies and molecular approaches are used to study remodeling of the left ventricle, atrial pathology is often ignored. Few studies have documented atrial dilation in experimental mouse models of pressure overload (21) and permanent coronary ligation (22); however, systematic characterization of atrial remodeling in experimental mouse models of heart disease has not been performed. The current study provides the first analysis of atrial remodeling, hypertrophy and fibrosis in mouse models of post-infarctive cardiac remodeling, pressure overload-induced cardiomyopathy and diabetic heart disease.

\subsection{MATERIALS AND METHODS}

\section{Animal protocols}

Animal experiments were conducted in accordance with the National Institutes of Health Guide for the Care and Use of Laboratory Animals and were approved by the Albert Einstein College of Medicine Institutional Review Board. 


\section{Mouse model of cardiac pressure overload induced through transverse aortic constriction} (TAC)

Male and female, 4-month old wildtype C57BL/6J mice (20.0-30.0 g body weight) were anesthetized with inhaled isoflurane and underwent transverse aortic constriction protocols for 7 days $(n=11)$ or 28 days $(n=8)$. Aortic banding was achieved by creating a constriction between the right innominate and left carotid arteries, as previously described (23),(24),(25), (26). The degree of pressure overload was assessed by measuring the right-to-left carotid artery flow velocity ratio after constricting the transverse aorta. Mice had echocardiographic analysis at baseline and after 7 and 28 days of TAC. At the end of the experiment, the animals were sacrificed and the hearts were excised, fixed in zinc-formalin, and embedded in paraffin for histological studies. Comparisons with a group of control mice $(n=7)$ was performed.

\section{Mouse model of non-reperfused myocardial infarction}

Male and female mice, 3-4 months of age (20.0-30.0 g body weight), were anesthetized using inhaled isoflurane and underwent permanent proximal left coronary artery occlusion protocols. Mortality was 55\%, observed during the first 6 days, primarily due to cardiac rupture. Surviving mice were followed for 7 days $(n=6)$, or 28 days $(n=10)$, as previously described (27). Briefly, anesthetized mice underwent thoracotomy and an 8.0 polypropylene suture with a U-shaped tapered needle was passed under the left anterior descending (LAD) coronary artery. Occlusion of the LAD was accomplished by ligating LAD until an STelevation appears on the ECG. Mice enrolled in the 28 day permanent occlusion group underwent echocardiography at baseline and prior to sacrifice. At the end of the experiment, the animals were sacrificed and the hearts were excised, fixed in zinc-formalin, and embedded in paraffin for histological studies. Findings were compared to a group of control mice $(n=7)$.

\section{Mouse model of diabetes-associated heart disease}

Lepr $^{\mathrm{db} /+}$ mice on a C57BL/6J background ( $\left.\mathrm{db} /+\right)$ were purchased from Jackson Laboratories (Bar Harbor, ME, USA). Heterozygous $\mathrm{db} /+$ mice were crossed in order to obtain $\mathrm{db} / \mathrm{db}$ mice and corresponding lean controls (28),(18). Genotyping was performed through established PCR protocols. At 6 months of age, $\mathrm{db} / \mathrm{db}$ mice $(\mathrm{n}=9)$ and corresponding control lean mice $(n=7)$ underwent echocardiography, then were sacrificed, and the hearts were excised, fixed in zinc-formalin, and embedded in paraffin for histological studies.

\section{Echocardiography}

Short axis M-mode and long-axis B-mode echocardiography was performed in anesthetized mice using the Vevo 2100 system (VisualSonics, Toronto ON). The following parameters were measured as indicators of function and ventricular remodeling: left ventricular enddiastolic volume (LVEDV), ejection fraction, end-diastolic left ventricular anterior wall thickness (LVAWTd), end-diastolic left ventricular posterior wall thickness (LVPWTd), and left ventricular mass (LV mass). Lean and diabetic mice underwent Doppler echocardiography and tissue Doppler imaging at 6 months of age to assess diastolic function using the Vevo 2100 system (VisualSonics). Transmitral LV inflow velocities were measured 
from apical 4-chamber view by pulsed-wave Doppler. Peak early E (E-wave) and late A (Awave) filling velocities and $\mathrm{E} / \mathrm{A}$ ratio were measured according to the guidelines of the American Society of Echocardiography (29). Tissue Doppler Imaging of the mitral annulus was obtained from the apical 4-chamber view. A 1.0-mm sample volume was placed sequentially at the medial mitral annulus. Analysis was performed for assessment of early (E ') diastolic velocity, and the $\mathrm{E} / \mathrm{E}^{\prime}$ ratio was calculated. Views and data were exported for offline calculation using Vevo 2100 quantification software (Vevo 2100 v.1.6.0). The offline analysis was performed by a sonographer blinded to study groups.

\section{Histological analysis and quantitative morphometry}

Formalin-fixed paraffin-embedded hearts were sectioned from base to apex at $250 \mu \mathrm{m}$ intervals as previously described (30). Ten serial $5-\mu \mathrm{m}$ sections were obtained at each interval, corresponding to an additional 50- $\mu \mathrm{m}$ segment. The first section from each interval was stained with hematoxylin/eosin. Each section was scanned at $\times 10$ magnification, the left atrium was identified, and the left atrial wall area (LAWA), left atrial chamber area (LACA), short and long axis of the atrium were measured using Axiovision LE 4.8 software (Zeiss). Assessment of left atrial volume and mass was performed by calculating the sum of the volumes of all 300- $\mu \mathrm{m}$ partitions. Because histological processing results in shrinkage of the processed tissue (31), the values were corrected by a linear factor of 1.3. The following formulas were used, adapted from our published work describing morphometric strategies used for assessment of ventricular remodeling following reperfused murine myocardial infarction (30):

$\mathrm{LA}$ volume $=(\mathrm{LACA} 1+\mathrm{LACA} 2+\ldots \ldots \ldots .+\mathrm{LACAn}) * \mathrm{~h}$, where $\mathrm{h}=0.3 \mathrm{~mm}$, LA wall volume $=(\mathrm{LAWA} 1+\mathrm{LAWA} 2+\ldots+\mathrm{LAWAn}) * \mathrm{~h}(\mathrm{~h}=0.3 \mathrm{~mm})$, and LA mass=LA wall volume $* 1.065 \mathrm{mg} / \mu \mathrm{l}($ specific gravity of myocardium $)$.

\section{Wheat Germ Agglutinin (WGA) lectin histochemistry, and quantitative assessment of cardiomyocyte size, interstitial fibrosis and interstitial cellularity}

In order to assess atrial cardiomyocyte hypertrophy in mouse models of heart disease, cardiomyocytes were outlined using WGA lectin histochemistry, using a WGA Alexa Fluor® 594 Conjugate (Life Technologies) (dilution 1:100). Sections were counterstained with DAPI. Cardiomyocyte size was quantitatively assessed using Axiovision LE 4.8 software (Zeiss). Fifty cardiomyocytes cut at cross-section were assessed from each mouse. Mean cardiomyocyte area was expressed in $\mu^{2}$. Interstitial fibrosis was assessed through quantitation of the WGA-stained interstitial area using Image Pro Plus software.

Quantitative assessment of the WGA-stained area has been validated as a reliable technique for evaluation of cardiac fibrosis (32). Quantitative assessment of interstitial cellularity in the left atrium was performed by counting the number of DAPI-positive interstitial nuclei per 
area of myocardium. Cell density was expressed as cells $/ \mathrm{mm}^{2}$. Six fields scanned at 400x magnification from two different stained sections were used for analysis of each mouse.

\section{Sirius red staining}

Light microscopy and polarized light microscopy was used to label collagen fibers in the atrium, as previously described (33),(19). Briefly, paraffin sections (5 $\mu$ thick) were stained using picrosirius red. Circularly polarized images were obtained using Axio Imager M2 for polarized light microscopy (Zeiss). When the collagen fibers are stained with picrosirius red and viewed with polarized light, depending on the thickness of the collagen fibers, the hues range from green to yellow to orange to red.

\section{Immunohistochemistry}

In order to study connexin 43 localization in remodeling atria, histological sections from 4 mice per group were stained immunohistochemically with rabbit anti-connexin43/GJA1 polyclonal antibody (Abcam, ab11370, dilution 1:1000). Staining was performed using a peroxidase-based technique with the Vectastain ELITE kit (Vector Labs). Following antigen retrieval with citrate buffer, sections were treated with $3 \%$ hydrogen peroxide to inhibit endogenous peroxidase activity and blocked with $10 \%$ goat serum to block nonspecific protein binding. Peroxidase activity was detected using diaminobenzidine with nickel. Negative controls were performed with incubation with rabbit IgG at the same concentration.

\section{Statistical analysis}

Statistical comparisons between more than 2 groups was performed using ANOVA followed by t-test corrected for multiple comparisons (Sidak's test). Comparisons between 2 groups were performed using t-test. Non Gaussian distributions were compared using the MannWhitney test. Data were expressed as mean \pm SEM. Statistical significance was set at 0.05 .

\subsection{RESULTS}

\section{Cardiac pressure overload causes left atrial hypertrophy and dilation}

TAC protocols induced comparable increases in R:L carotid velocity ratio in the 7 (7.5 \pm 0.94$)$ and 28 day group ( $9.0 \pm 1.04)$, suggesting similar pressure loads. The effects of pressure overload protocols on left ventricular geometry and function are shown in Table 1. After 7 days of TAC, mice exhibited early concentric left ventricular hypertrophy, followed by modest dilation and systolic dysfunction after 28 days. Pressure overload induced through TAC caused left atrial dilation and hypertrophy (Figure 1A), evidenced by marked and progressive increases in left atrial volume and left atrial mass after 7-28 days (Figure $1 \mathrm{~B}-\mathrm{C})$. TAC reduced sphericity of the atrium, causing a marked increase in the long axis dimension, accompanied by a less impressive increase in the short axis (Figure 1D, E).

\section{Alterations of atrial geometry following non-reperfused myocardial infarction}

Permanent left coronary artery occlusion caused transmural left ventricular myocardial infarction in all mice studied, accompanied by severe systolic dysfunction and dilative 
ventricular remodeling (Table 2). Post-infarctive LV remodeling was associated with marked left atrial hypertrophy and dilation (Figure 2A). Left atrial volume and left atrial mass markedly increased in infarcted animals 7-28 days after coronary occlusion (Figure 2B-C). Infarction was associated with a marked increase in long axis dimensions (Figure 2D); in contrast, the increase in short-axis did not reach statistical significance (Figure 2E) suggesting eccentric dilation of the atrium.

\section{Diabetic hearts exhibit atrial remodeling}

At 6 months of age, $\mathrm{db} / \mathrm{db}$ mice exhibited marked obesity (body weight: $\mathrm{db} / \mathrm{db}$ mice $59.7 \pm 6.42 \mathrm{gm}$ vs. WT mice $22.8 \pm 0.8 \mathrm{gm}, \mathrm{p}<0.01)$. Echocardiographic analysis showed that $\mathrm{db} / \mathrm{db}$ mice had a significant increase in LVPWTd and a trend towards an increase in LV mass (Table 3). Doppler echocardiography showed that $\mathrm{db} / \mathrm{db}$ mice had significantly higher $\mathrm{E} / \mathrm{E}^{\prime}$ ratio; this finding is consistent with worse diastolic function (Table 3). $\mathrm{db} / \mathrm{db}$ mice developed atrial dilation and hypertrophy evidenced by markedly increased LA volume and LA mass (Figure $3 \mathrm{~A}-\mathrm{C}$ ). db/db mice had significantly increased long axis, but not short axis dimensions, suggesting eccentric remodeling of the atrium (Figure 3D-E).

\section{Atrial cardiomyocyte hypertrophy and interstitial fibrosis in mouse models of left ventricular remodeling}

Histologic analysis showed progressive loss of contractile elements in atrial cardiomyocytes of pressure-overloaded or infarcted animals, but not in obese diabetic mice (Figures 4-6). Evidence of left atrial cardiomyocyte hypertrophy was noted in all three models of left ventricular remodeling. In the model of cardiac pressure overload, the atrial myocardium showed loss of contractile elements in a subset of cardiomyocytes after 7-28 days of TAC (Figure 4A-D). Sirius red staining visualized with light (Figure 4E-G) and polarized (Figure 4H-J) microscopy showed significant atrial interstitial fibrosis after 7-28 days of TAC. Quantitative analysis showed that left atrial cardiomyocytes exhibited a marked and progressive increase in size after 7-28 days of TAC (Figure $4 \mathrm{~K}-\mathrm{N}$ ).

Following myocardial infarction, some atrial cardiomyocytes exhibited marked loss of contractile elements and significant myocytolysis (Figure 5A-D). Sirius red staining visualized with light and polarized microscopy showed significant fibrosis in the atrial myocardium, 7-28 days after myocardial infarction (Figure 5E-J). Quantitative analysis showed that atrial cardiomyocyte area was markedly increased after 7 days, and remained increased after 28 days of coronary occlusion (Figure 5K-N). In 6-month old obese diabetic $\mathrm{db} / \mathrm{db}$ mice, atrial cardiomyocyte morphology was relatively preserved (Figure 6A-C). Sirius red staining showed that $\mathrm{db} / \mathrm{db}$ mice exhibit mild atrial fibrosis. Atrial cardiomyocyte size was significantly increased in $\mathrm{db} / \mathrm{db}$ mice, when compared with age-matched lean animals (Figure 6H-L).

Remodeling hearts also exhibited significant atrial fibrosis, evidenced by a marked expansion of the atrial interstitium, identified through sirius red and WGA lectin histochemical staining. Cardiac pressure overload was associated with a marked 5-fold expansion of the atrial interstitium after 7-28 days of TAC (Figure 4O). Non-reperfused myocardial infarction was associated with a 6-fold increase in atrial interstitial area after $7-$ 
28 days of permanent coronary occlusion (Figure 5O). db/db mice had a 2 -fold increase in atrial WGA-stained area, reflecting significant widening of the atrial interstitium in obese diabetic animals (Figure 6M).

Atrial fibrosis was associated with increased interstitial cellular content in all 3 models of left ventricular disease. Cardiac pressure overload was associated with a 4-fold increase in interstitial cellularity after 7-28 days of TAC (Figure 4P). Following non-reperfused myocardial infarction, atrial interstitial density exhibited a 3-fold increase after 7 and 28 days of coronary occlusion (Figure 5P). db/db hearts exhibited a 50\% increase in interstitial cellularity when compared with lean mouse hearts (Figure $6 \mathrm{~N}$ ).

\section{Localization of connexin43 in remodeling atria}

Because changes in connexin expression have been linked with atrial arrhythmias we examined connexin-43 localization in remodeling atria. In normal left atrium, connexin-43 was localized in intercalated discs (Figure 7A). Following myocardial infarction, atrial connexin-43 immunoreactivity was markedly reduced and exhibited heterogeneous distribution and lateralization (Figure 7B-C). Pressure overloaded hearts also exhibited attenuated atrial connexin-43 expression, accompanied by lateralization (Figure 7D-E). In contrast, $\mathrm{db} / \mathrm{db}$ mice did not have significant changes in atrial connexin-43 expression (Figure 7F).

\subsection{DISCUSSION}

In human patients, assessment of atrial size and geometry serves as a window to cardiac hemodynamics and diastolic function. In contrast to Doppler indices of diastolic function, which are sensitive to changes in preload and afterload (34), left atrial size may be a more stable indicator that reflects the duration and severity of diastolic dysfunction (35).

Although, left atrial volume has been extensively used as a relevant functional endpoint in assessment of diastolic function in large animal models of cardiac injury (36), changes in atrial geometry and structure are seldom studied in mouse models of left ventricular disease. This is due in part to technical challenges in evaluation of the left atrium in mice, and in part to the absence of evidence characterizing the structural and geometric changes of the left atrium following murine cardiac injury. Our study provides a systematic descriptive analysis of atrial remodeling in 3 clinically relevant mouse models of left ventricular disease.

\section{Atrial cardiomyopathy in mouse models of left ventricular disease}

In the clinical context, the term "atrial cardiomyopathy" is used to describe a wide range of structural, functional and electrophysiological alterations of the atria, capable of producing clinical manifestations (37). A recent histopathological classification defined 4 classes of atrial cardiomyopathies, on the basis of the predominant underlying pathology: class I shows primarily cardiomyocyte changes, class II exhibits principally fibrotic remodeling, class III shows a combination of cardiomyocyte and fibrotic alterations, and class IV is characterized by deposition of non-collagenous material or inflammatory infiltration, in the presence or absence of cardiomyocyte alterations (37). Our findings in 3 different mouse models of left ventricular disease suggest the presence of an atrial cardiomyopathy with class III 
characteristics. Mice undergoing TAC protocols and animals with non-reperfused myocardial infarction exhibited loss of contractile material in a subset of cardiomyocytes, associated with progressive hypertrophy and fibrosis (Figures 4 and 5). Obese diabetic mice had less severe atrial pathology, exhibiting mild atrial cardiomyocyte hypertrophy and atrial fibrosis (Figure 6). The morphological and histopathological changes in the mouse models of left ventricular disease are summarized in Table 4.

\section{Atrial remodeling and fibrosis in response to cardiac pressure overload}

Using quantitative morphometry, we demonstrated that pressure overload causes marked increases in left atrial volume and left atrial mass, and reduced sphericity of the chamber, as early as 7 days after TAC (Figure 1). These changes were associated with evidence of atrial fibrosis and atrial cardiomyocyte hypertrophy (Figure 4). Published studies have documented dilative atrial remodeling in mouse models of pressure overload. Using echocardiographic analysis, Zile and co-workers (38) showed a late increase in left atrial dimensions, 4 weeks after TAC. Late detection of atrial remodeling may reflect the challenges in echocardiographic visualization of the mouse atria and the eccentric pattern of remodeling. Moreover, in male mice undergoing TAC protocols, De Jong and colleagues noted a progressive atrial hypertrophy, accompanied with increases in atrial expression of extracellular matrix proteins, such as collagen I, III and fibronectin (21). The authors did not document histological evidence of atrial fibrosis; however, the limited sensitivity of the trichrome stain used to assess the atrial interstitial matrix (22) may explain these negative findings.

\section{Atrial remodeling following myocardial infarction}

Our findings documented eccentric left atrial dilation, hypertrophy and left atrial fibrosis in mice with large non-reperfused left coronary artery territory infarcts (Figure 2, 5). The findings are consistent with similar observations by Colazzo and co-workers (22) that demonstrated echocardiographic evidence of increased left atrial dimensions 4 weeks after coronary occlusion. Although increased filling pressures due to the extensive left ventricular dysfunction likely account for the alterations in atrial geometry and architecture observed in infarcted animals, a subset of mice exhibited small areas of left atrial infarction that may contribute to atrial remodeling.

\section{Atrial remodeling in diabetes, obesity and metabolic dysfunction}

Obese and diabetic subjects exhibit increases in left atrial volumes, even in the absence of hypertension, or overt cardiovascular disease (39); these changes are accompanied by an increased incidence of atrial tachyarrhythmias (40). Our findings show that mice with obesity and diabetes due to genetic central leptin resistance, have significant atrial dilation and increased left atrial mass, associated with atrial cardiomyocyte hypertrophy, fibrosis and a 50\% increase in interstitial cellularity (Figure 6). Consistent with our findings, published studies have demonstrated significant atrial fibrosis in rats with type 1 or type 2 diabetes (41),(42). In contrast, in mouse models of diabetes, atrial fibrosis has not been consistently documented. In adult male mice, a high fat diet for 2 months increased the vulnerability to atrial arrhythmias, without causing atrial fibrosis (43). 
Atrial remodeling in obese diabetic subjects may reflect elevations in left ventricular filling pressures due to diastolic dysfunction, but may also result from direct effects of metabolic dysregulation on atrial cardiomyocytes and fibroblasts (44). Diabetes-associated generation of reactive oxygen species, activation of AGE (advanced glycation end-products)-RAGE (receptor for AGE) signaling, and stimulation of angiotensin II or growth factor pathways may activate atrial fibroblasts triggering left atrial fibrosis (45). In patients with coronary disease, diabetes was associated with an activated atrial fibroblast phenotype, showing a 2fold increase in collagen transcription (46).

\section{Connexin remodeling: a potential link between structural alterations and atrial tachyarrhythmias}

Atrial remodeling is often associated with atrial tachyarrhythmias; however, the molecular links between structural changes and arrhythmia generation remain poorly understood. Gap junctions are specialized intercellular connections that enable propagation of the electrical impulse and consist of 4 transmembrane proteins, members of the connexin family (47). In both experimental models and in human patients, atrial fibrillation is associated with alterations in the levels of expression and in localization of the connexins (48),(49). However, the patterns of these changes are often inconsistent in various models (47). Our findings demonstrate a marked attenuation in connexin- 43 immunoreactivity in the left atrium of mice undergoing pressure overload, or myocardial infarction protocols (Figure 7). Reduced expression of connexin-43 in remodeling atria was associated with "lateralization", ectopic expression of connexin-43 along the major axis of the cardiomyocytes, instead of the typical localization in intercalated disks. Whether gap junctional remodeling may trigger atrial fibrillation in mouse models of left ventricular disease remains unknown.

\section{Conclusions}

Much like in human patients, mouse models of left ventricular disease exhibit left atrial remodeling. Considering the prognostic value of atrial size parameters in patients with cardiovascular disease, assessment of left atrial mass, volume, and geometric remodeling may represent an important tool for functional evaluation, in particular in studies investigating the chronic consequences of diastolic dysfunction. Moreover, dissection of the cell biological mechanisms responsible for atrial fibrosis may contribute to our understanding of the pathogenesis of atrial tachyarrhythmias.

\section{Acknowledgments}

SOURCES OF FUNDING: Supported by grants from the National Institutes of Health (R01 HL76246 and R01 HL85440 to N.G.F.), the Department of Defense (PR151134 and PR151029 to N.G.F.) and the American Heart Association Founders' affiliate (to A.V.S.).

\section{References}

1. Pritchett AM, Mahoney DW, Jacobsen SJ, Rodeheffer RJ, Karon BL, Redfield MM. Diastolic dysfunction and left atrial volume: a population-based study. J Am Coll Cardiol. 2005; 45(1):87-92. [PubMed: 15629380] 
2. Moller JE, Hillis GS, Oh JK, Seward JB, Reeder GS, Wright RS, Park SW, Bailey KR, Pellikka PA. Left atrial volume: a powerful predictor of survival after acute myocardial infarction. Circulation. 2003; 107(17):2207-12. [PubMed: 12695291]

3. Beinart R, Boyko V, Schwammenthal E, Kuperstein R, Sagie A, Hod H, Matetzky S, Behar S, Eldar M, Feinberg MS. Long-term prognostic significance of left atrial volume in acute myocardial infarction. J Am Coll Cardiol. 2004; 44(2):327-34. [PubMed: 15261927]

4. Yang WI, Shim CY, Kim YJ, Kim SA, Rhee SJ, Choi EY, Choi D, Jang Y, Chung N, Cho SY, et al. Left atrial volume index: a predictor of adverse outcome in patients with hypertrophic cardiomyopathy. J Am Soc Echocardiogr. 2009; 22(12):1338-43. [PubMed: 19879733]

5. Sabharwal N, Cemin R, Rajan K, Hickman M, Lahiri A, Senior R. Usefulness of left atrial volume as a predictor of mortality in patients with ischemic cardiomyopathy. Am J Cardiol. 2004; 94(6): 760-3. [PubMed: 15374781]

6. Rossi A, Cicoira M, Bonapace S, Golia G, Zanolla L, Franceschini L, Vassanelli C. Left atrial volume provides independent and incremental information compared with exercise tolerance parameters in patients with heart failure and left ventricular systolic dysfunction. Heart. 2007; 93(11):1420-5. [PubMed: 17164482]

7. Poulsen MK, Dahl JS, Henriksen JE, Hey TM, Hoilund-Carlsen PF, Beck-Nielsen H, Moller JE. Left atrial volume index: relation to long-term clinical outcome in type 2 diabetes. J Am Coll Cardiol. 2013; 62(25):2416-21. [PubMed: 24076532]

8. Kizer JR, Bella JN, Palmieri V, Liu JE, Best LG, Lee ET, Roman MJ, Devereux RB. Left atrial diameter as an independent predictor of first clinical cardiovascular events in middle-aged and elderly adults: the Strong Heart Study (SHS). Am Heart J. 2006; 151(2):412-8. [PubMed: 16442908]

9. Corradi D. Atrial fibrillation from the pathologist's perspective. Cardiovasc Pathol. 2014; 23(2):7184. [PubMed: 24462196]

10. Thomas L, Abhayaratna WP. Left Atrial Reverse Remodeling: Mechanisms, Evaluation, and Clinical Significance. JACC Cardiovasc Imaging. 2017; 10(1):65-77. [PubMed: 28057220]

11. Tanaka K, Zlochiver S, Vikstrom KL, Yamazaki M, Moreno J, Klos M, Zaitsev AV, Vaidyanathan R, Auerbach DS, Landas S, et al. Spatial distribution of fibrosis governs fibrillation wave dynamics in the posterior left atrium during heart failure. Circ Res. 2007; 101(8):839-47. [PubMed: 17704207]

12. Nattel S. How does fibrosis promote atrial fibrillation persistence: in silico findings, clinical observations, and experimental data. Cardiovasc Res. 2016; 110(3):295-7. [PubMed: 27131507]

13. Hirsh BJ, Copeland-Halperin RS, Halperin JL. Fibrotic atrial cardiomyopathy, atrial fibrillation, and thromboembolism: mechanistic links and clinical inferences. J Am Coll Cardiol. 2015; 65(20): 2239-51. [PubMed: 25998669]

14. Frangogiannis NG. Pathophysiology of Myocardial Infarction. Compr Physiol. 2015; 5(4):184175. [PubMed: 26426469]

15. Rai V, Sharma P, Agrawal S, Agrawal DK. Relevance of mouse models of cardiac fibrosis and hypertrophy in cardiac research. Mol Cell Biochem. 2017; 424(1-2):123-45. [PubMed: 27766529]

16. Kong P, Christia P, Frangogiannis NG. The pathogenesis of cardiac fibrosis. Cell Mol Life Sci. 2014; 71(4):549-74. [PubMed: 23649149]

17. Kemp CD, Conte JV. The pathophysiology of heart failure. Cardiovasc Pathol. 2012; 21(5):365-71. [PubMed: 22227365]

18. Gonzalez-Quesada C, Cavalera M, Biernacka A, Kong P, Lee DW, Saxena A, Frunza O, Dobaczewski M, Shinde A, Frangogiannis NG. Thrombospondin-1 induction in the diabetic myocardium stabilizes the cardiac matrix in addition to promoting vascular rarefaction through angiopoietin-2 upregulation. Circ Res. 2013; 113(12):1331-44. [PubMed: 24081879]

19. Shinde AV, Dobaczewski M, de Haan JJ, Saxena A, Lee KK, Xia Y, Chen W, Su Y, Hanif W, Madahar IK, et al. Tissue transglutaminase induction in the pressure-overloaded myocardium regulates matrix remodeling. Cardiovasc Res. 2017 Mar.:28. (epub ahead of print). doi: $10.1093 / \mathrm{cvr} / \mathrm{cvx} 053$

20. Frangogiannis NG. The extracellular matrix in myocardial injury, repair, and remodeling. J Clin Invest. 2017; 127(5):1600-12. [PubMed: 28459429] 
21. De Jong AM, Van Gelder IC, Vreeswijk-Baudoin I, Cannon MV, Van Gilst WH, Maass AH. Atrial remodeling is directly related to end-diastolic left ventricular pressure in a mouse model of ventricular pressure overload. PLoS One. 2013; 8(9):e72651. [PubMed: 24039788]

22. Colazzo F, Castiglioni L, Sironi L, Fontana L, Nobili E, Franzosi M, Guerrini U. Murine left atrium and left atrial appendage structure and function: echocardiographic and morphologic evaluation. PLoS One. 2015; 10(4):e0125541. [PubMed: 25928887]

23. Rockman HA, Ross RS, Harris AN, Knowlton KU, Steinhelper ME, Field LJ, Ross J Jr, Chien KR. Segregation of atrial-specific and inducible expression of an atrial natriuretic factor transgene in an in vivo murine model of cardiac hypertrophy. Proc Natl Acad Sci U S A. 1991; 88(18):8277-81. [PubMed: 1832775]

24. Xia Y, Lee K, Li N, Corbett D, Mendoza L, Frangogiannis NG. Characterization of the inflammatory and fibrotic response in a mouse model of cardiac pressure overload. Histochem Cell Biol. 2009; 131(4):471-81. [PubMed: 19030868]

25. Frunza O, Russo I, Saxena A, Shinde AV, Humeres C, Hanif W, Rai V, Su Y, Frangogiannis NG. Myocardial Galectin-3 Expression Is Associated with Remodeling of the Pressure-Overloaded Heart and May Delay the Hypertrophic Response without Affecting Survival, Dysfunction, and Cardiac Fibrosis. Am J Pathol. 2016; 186(5):1114-27. [PubMed: 26948424]

26. Xia Y, Dobaczewski M, Gonzalez-Quesada C, Chen W, Biernacka A, Li N, Lee DW, Frangogiannis NG. Endogenous thrombospondin 1 protects the pressure-overloaded myocardium by modulating fibroblast phenotype and matrix metabolism. Hypertension. 2011; 58(5):902-11. [PubMed: 21947471]

27. Saxena A, Shinde AV, Haque Z, Wu YJ, Chen W, Su Y, Frangogiannis NG. The role of Interleukin Receptor Associated Kinase (IRAK)-M in regulation of myofibroblast phenotype in vitro, and in an experimental model of non-reperfused myocardial infarction. J Mol Cell Cardiol. 2015; 89(Pt B):223-31. [PubMed: 26542797]

28. Biernacka A, Cavalera M, Wang J, Russo I, Shinde A, Kong P, Gonzalez-Quesada C, Rai V, Dobaczewski M, Lee DW, et al. Smad3 Signaling Promotes Fibrosis While Preserving Cardiac and Aortic Geometry in Obese Diabetic Mice. Circ Heart Fail. 2015; 8(4):788-98. [PubMed: 25985794]

29. Nagueh SF, Appleton CP, Gillebert TC, Marino PN, Oh JK, Smiseth OA, Waggoner AD, Flachskampf FA, Pellikka PA, Evangelista A. Recommendations for the evaluation of left ventricular diastolic function by echocardiography. J Am Soc Echocardiogr. 2009; 22(2):107-33. [PubMed: 19187853]

30. Christia P, Bujak M, Gonzalez-Quesada C, Chen W, Dobaczewski M, Reddy A, Frangogiannis NG. Systematic characterization of myocardial inflammation, repair, and remodeling in a mouse model of reperfused myocardial infarction. J Histochem Cytochem. 2013; 61(8):555-70. [PubMed: 23714783]

31. Kerns MJ, Darst MA, Olsen TG, Fenster M, Hall P, Grevey S. Shrinkage of cutaneous specimens: formalin or other factors involved? J Cutan Pathol. 2008; 35(12):1093-6. [PubMed: 18544064]

32. Emde B, Heinen A, Godecke A, Bottermann K. Wheat germ agglutinin staining as a suitable method for detection and quantification of fibrosis in cardiac tissue after myocardial infarction. Eur J Histochem. 2014; 58(4):2448. [PubMed: 25578975]

33. Whittaker P, Kloner RA, Boughner DR, Pickering JG. Quantitative assessment of myocardial collagen with picrosirius red staining and circularly polarized light. Basic Res Cardiol. 1994; 89(5):397-410. [PubMed: 7535519]

34. Hurrell DG, Nishimura RA, Ilstrup DM, Appleton CP. Utility of preload alteration in assessment of left ventricular filling pressure by Doppler echocardiography: a simultaneous catheterization and Doppler echocardiographic study. J Am Coll Cardiol. 1997; 30(2):459-67. [PubMed: 9247519]

35. Simek CL, Feldman MD, Haber HL, Wu CC, Jayaweera AR, Kaul S. Relationship between left ventricular wall thickness and left atrial size: comparison with other measures of diastolic function. J Am Soc Echocardiogr. 1995; 8(1):37-47. [PubMed: 7710749]

36. Ishikawa K, Aguero J, Oh JG, Hammoudi N, Fish LA, Leonardson L, Picatoste B, Santos-Gallego CG, Fish KM, Hajjar RJ. Increased stiffness is the major early abnormality in a pig model of severe aortic stenosis and predisposes to congestive heart failure in the absence of systolic dysfunction. J Am Heart Assoc. 2015; 4(5) 
37. Goette A, Kalman JM, Aguinaga L, Akar J, Cabrera JA, Chen SA, Chugh SS, Corradi D, D'Avila A, Dobrev D, et al. EHRA/HRS/APHRS/SOLAECE expert consensus on atrial cardiomyopathies: definition, characterization, and clinical implication. Europace. 2016; 18(10):1455-90. [PubMed: 27402624]

38. Zile MR, Baicu CF, Stroud RE, Van Laer A, Arroyo J, Mukherjee R, Jones JA, Spinale FG. Pressure overload-dependent membrane type 1-matrix metalloproteinase induction: relationship to LV remodeling and fibrosis. Am J Physiol Heart Circ Physiol. 2012; 302(7):H1429-37. [PubMed: 22287584]

39. Atas H, Kepez A, Atas DB, Kanar BG, Dervisova R, Kivrak T, Tigen MK. Effects of diabetes mellitus on left atrial volume and functions in normotensive patients without symptomatic cardiovascular disease. J Diabetes Complications. 2014; 28(6):858-62. [PubMed: 25130919]

40. Goudis CA, Korantzopoulos P, Ntalas IV, Kallergis EM, Ketikoglou DG. Obesity and atrial fibrillation: A comprehensive review of the pathophysiological mechanisms and links. J Cardiol. 2015; 66(5):361-9. [PubMed: 25959929]

41. Saito S, Teshima Y, Fukui A, Kondo H, Nishio S, Nakagawa M, Saikawa T, Takahashi N. Glucose fluctuations increase the incidence of atrial fibrillation in diabetic rats. Cardiovasc Res. 2014; 104(1):5-14. [PubMed: 25082849]

42. Linz D, Hohl M, Dhein S, Ruf S, Reil JC, Kabiri M, Wohlfart P, Verheule S, Bohm M, Sadowski T, et al. Cathepsin A mediates susceptibility to atrial tachyarrhythmia and impairment of atrial emptying function in Zucker diabetic fatty rats. Cardiovasc Res. 2016; 110(3):371-80. [PubMed: 27032673]

43. Takahashi K, Sasano T, Sugiyama K, Kurokawa J, Tamura N, Soejima Y, Sawabe M, Isobe M, Furukawa T. High-fat diet increases vulnerability to atrial arrhythmia by conduction disturbance via miR-27b. J Mol Cell Cardiol. 2016; 90:38-46. [PubMed: 26654778]

44. Cavalera M, Wang J, Frangogiannis NG. Obesity, metabolic dysfunction, and cardiac fibrosis: pathophysiological pathways, molecular mechanisms, and therapeutic opportunities. Transl Res. 2014; 164(4):323-35. [PubMed: 24880146]

45. Russo I, Frangogiannis NG. Diabetes-associated cardiac fibrosis: Cellular effectors, molecular mechanisms and therapeutic opportunities. J Mol Cell Cardiol. 2016; 90:84-93. [PubMed: 26705059]

46. Sedgwick B, Riches K, Bageghni SA, O’Regan DJ, Porter KE, Turner NA. Investigating inherent functional differences between human cardiac fibroblasts cultured from nondiabetic and Type 2 diabetic donors. Cardiovasc Pathol. 2014; 23(4):204-10. [PubMed: 24746387]

47. Corradi D, Callegari S, Maestri R, Benussi S, Alfieri O. Structural remodeling in atrial fibrillation. Nat Clin Pract Cardiovasc Med. 2008; 5(12):782-96. [PubMed: 18852714]

48. Polontchouk L, Haefliger JA, Ebelt B, Schaefer T, Stuhlmann D, Mehlhorn U, Kuhn-Regnier F, De Vivie ER, Dhein S. Effects of chronic atrial fibrillation on gap junction distribution in human and rat atria. J Am Coll Cardiol. 2001; 38(3):883-91. [PubMed: 11527649]

49. Kostin S, Klein G, Szalay Z, Hein S, Bauer EP, Schaper J. Structural correlate of atrial fibrillation in human patients. Cardiovasc Res. 2002; 54(2):361-79. [PubMed: 12062341] 


\section{HIGHLIGHTS}

In a mouse model of cardiac pressure overload, left ventricular remodeling is associated with left atrial dilation, hypertrophy and fibrosis.

Following left ventricular infarction, mice exhibit marked left atrial remodeling and fibrosis.

Obese diabetic mice have atrial dilation, hypertrophy and mild atrial fibrosis.

Mice with post-infarction heart failure, or pressure overload exhibit myofibrillar loss in atrial cardiomyocytes and perturbed localization of connexin- 43 . 


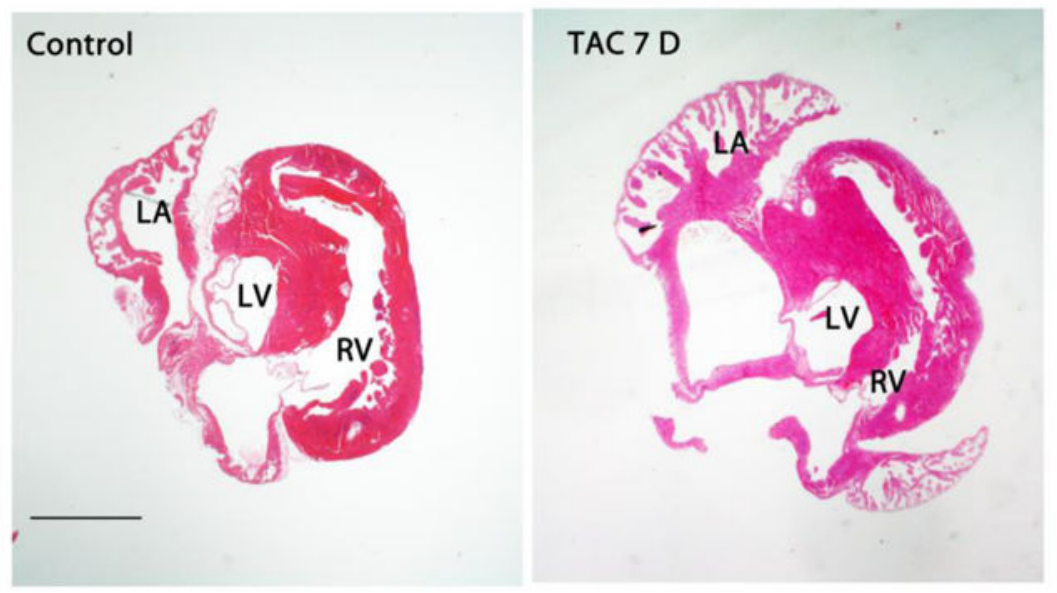

A

B
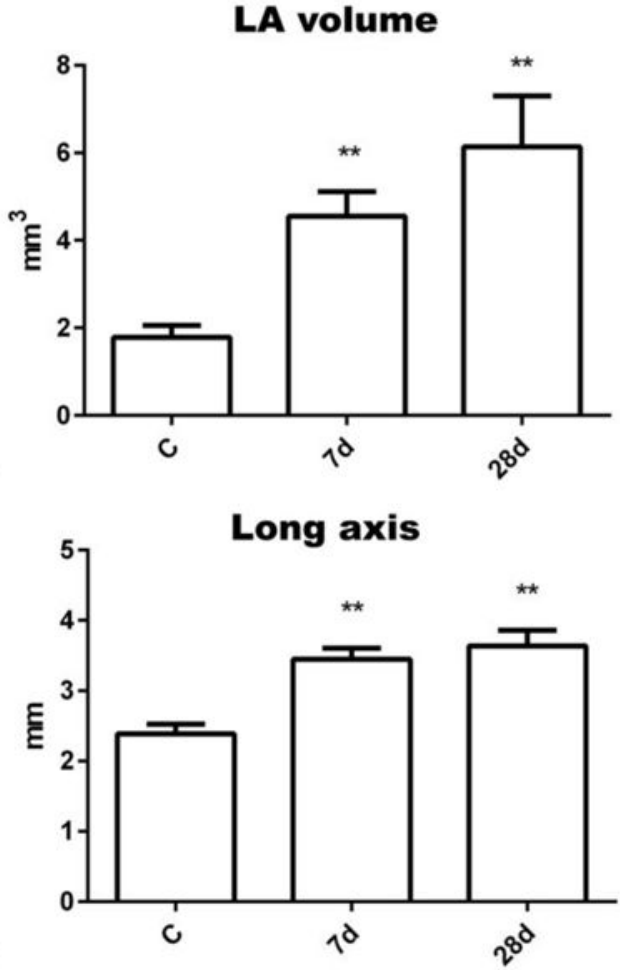

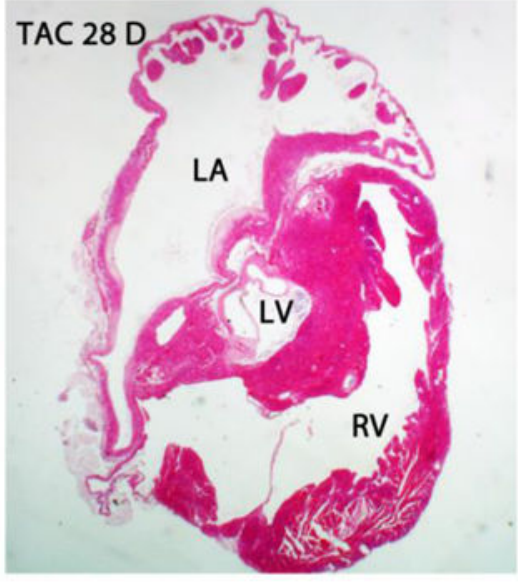

LA mass

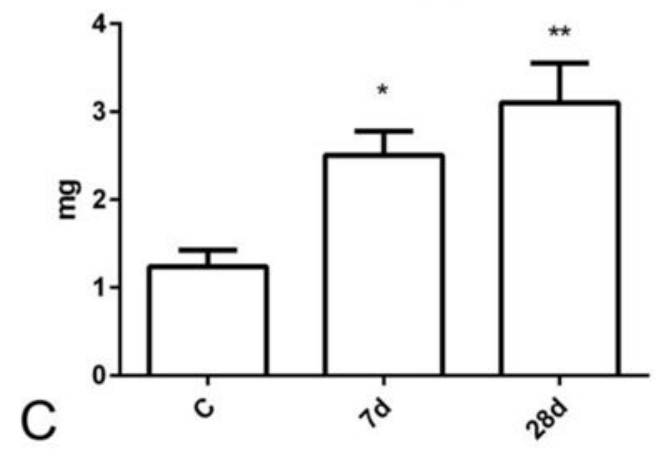

Short axis

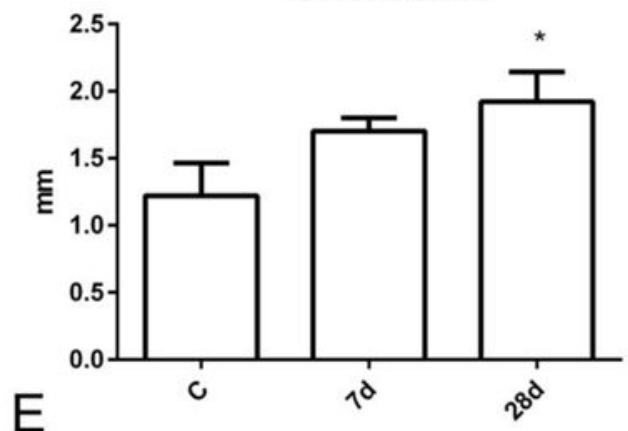

Figure 1. Cardiac pressure overload induces left atrial remodeling

Following TAC, adult mice developed marked concentric left ventricular hypertrophy, followed by late depression of left ventricular systolic function and chamber dilation (Table 1). A. Hearts were sectioned from base to apex, left atrial volumes and mass was assessed using quantitative morphometric analysis. TAC was associated with a marked increase in left atrial (LA) size. Representative images show H\&E-stained sections from a control mouse and from animals sacrificed after 7 and 28 days of TAC. Quantitative analysis showed that pressure overload induced a marked increase in LA volume (B) and LA mass (C). TAC was associated with a marked increase in the long axis dimension (D) of the LA, and a much less impressive increase in the short axis dimension (E), suggesting eccentric remodeling 
$\left({ }^{*} \mathrm{p}<0.05,{ }^{* *} \mathrm{p}<0.01\right.$ vs. control, $\mathrm{n}=7-11$ /group). Additional symbols: $\mathrm{LV}$, left ventricle; $\mathrm{RV}$, right ventricle (scalebar $=1 \mathrm{~mm}$ ). 


$$
\text { C }
$$

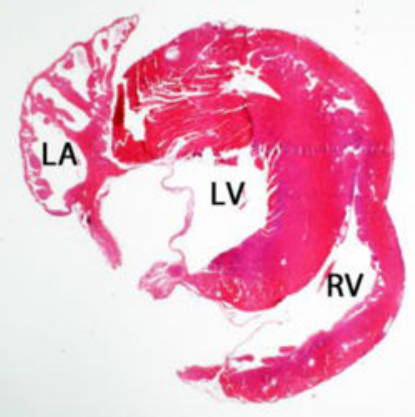

A
LA volume

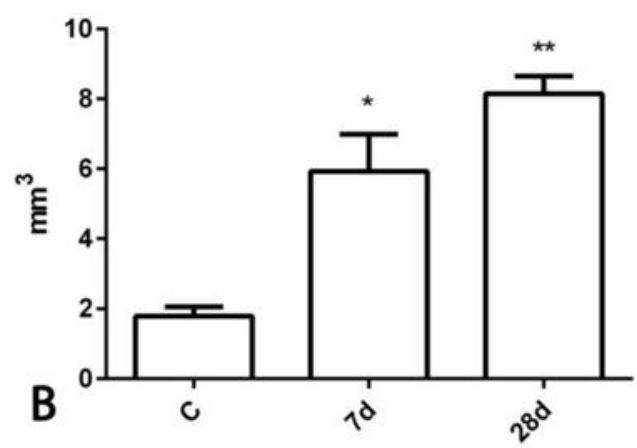

LA long axis

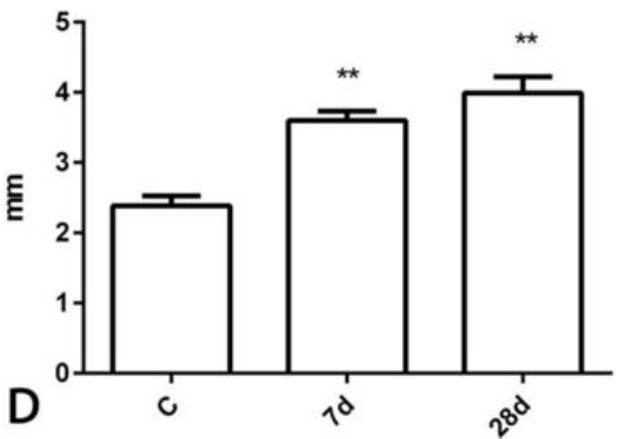

$7 d$

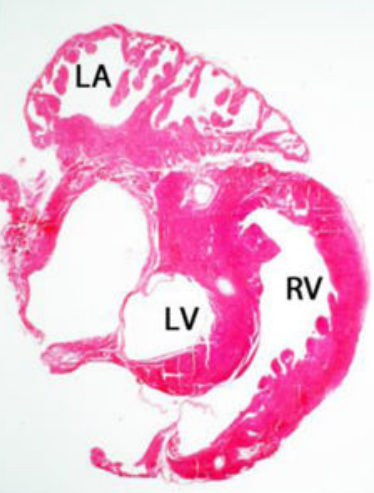

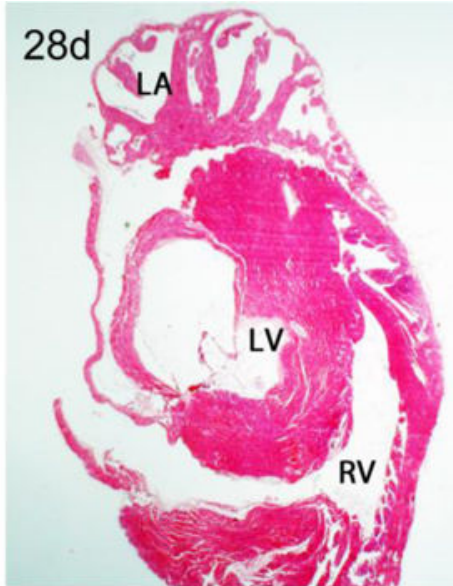

LA mass

Figure 2. Left atrial remodeling following non-reperfused myocardial infarction Non-reperfused myocardial infarction is associated with marked left ventricular dilation and systolic dysfunction (Table 2). A. Infarcted mouse hearts exhibit marked increases in LA size. Morphometric analysis showed that LA volume (B) and LA mass (C) are markedly increased 7-28 days after myocardial infarction. Atrial remodeling is characterized by marked increase in the long axis dimension (D), but no significant effect on the short axis dimension (E), suggesting eccentric remodeling ( ${ }^{*} \mathrm{p}<0.05,{ }^{*} \mathrm{p}<0.01$ vs. control, $\mathrm{n}=6-10$ / group) (scalebar $=1 \mathrm{~mm}$ ). 


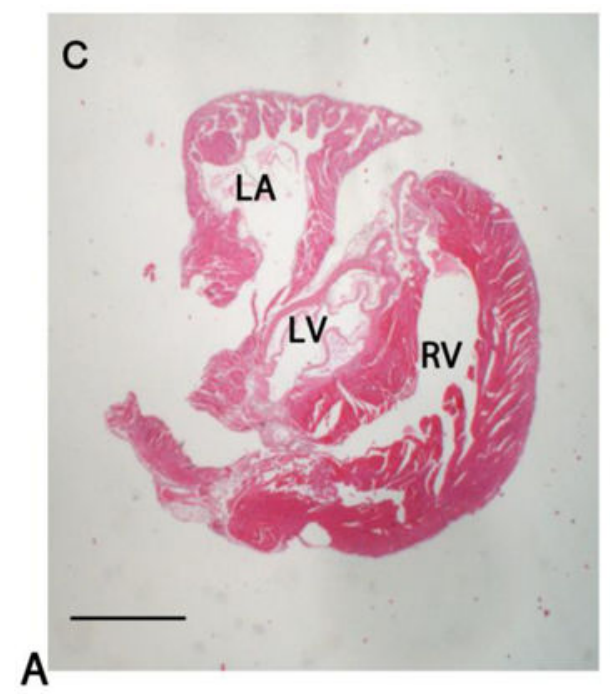

LA volume

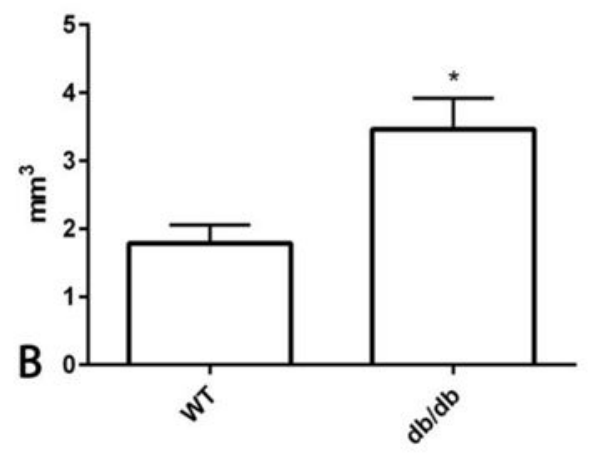

LA long axis

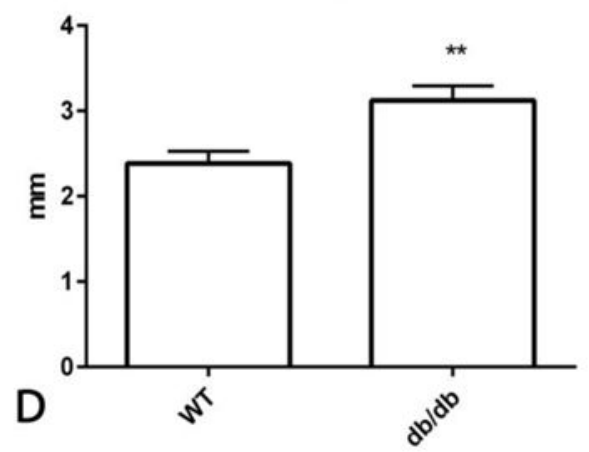

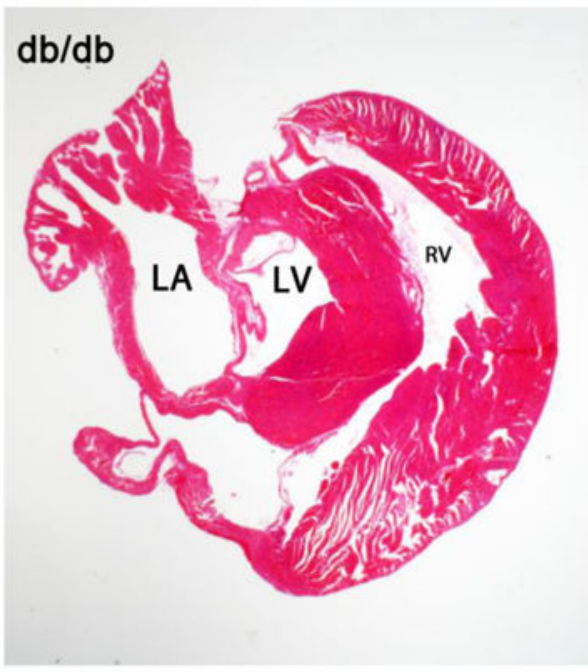

LA mass

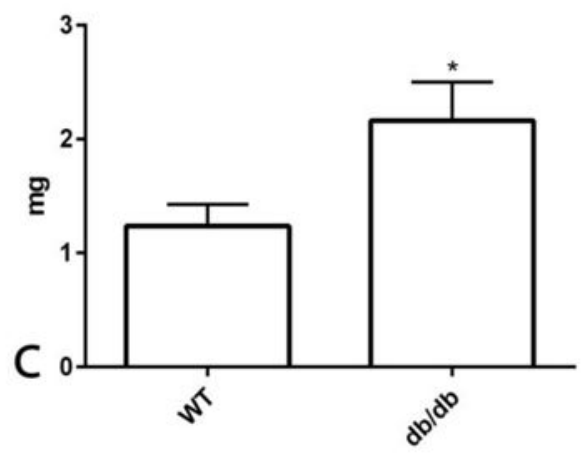

LA Short axis

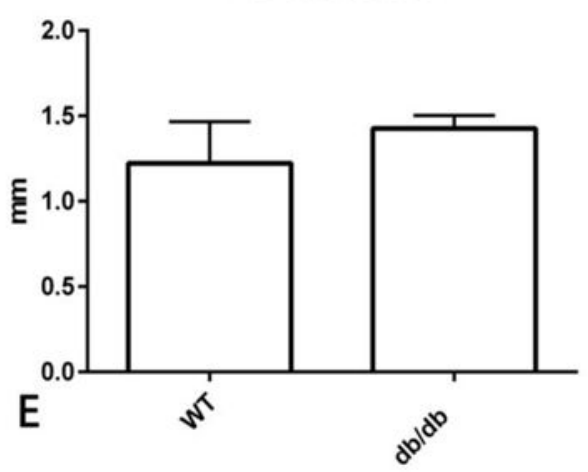

Figure 3. Left atrial remodeling in diabetic mice At 6 months of age, $\mathrm{db} / \mathrm{db}$ mice exhibited a trend towards increased LV mass and evidence of diastolic dysfunction (Table 3). A. These changes were associated with significantly increased LA size. Morphometric analysis showed that LA volume (B) and LA mass (C) were significantly higher in $\mathrm{db} / \mathrm{db}$ mice, when compared with lean controls. There was a significant increase in the long axis LA dimension (D) without a significant difference in the LA short axis dimension (E), suggesting eccentric atrial remodeling (scalebar=1mm). 


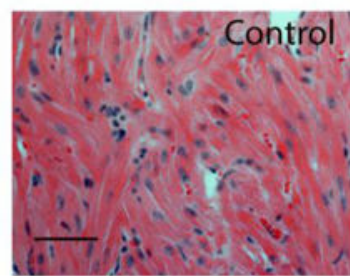

A

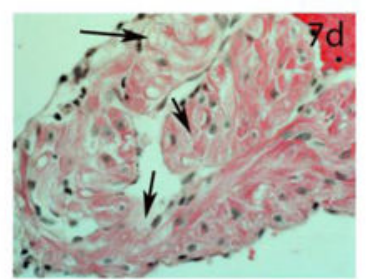

B

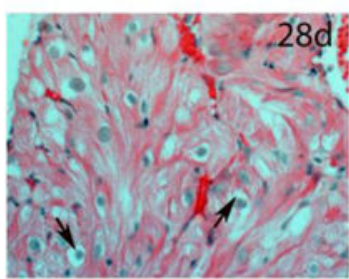

c

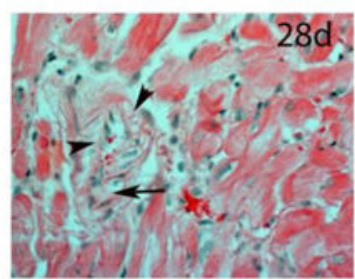

D

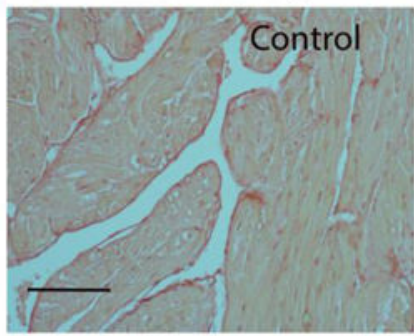

E

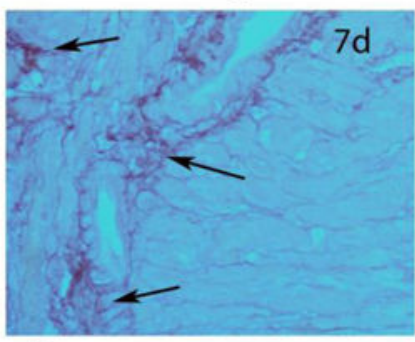

$\mathrm{F}$

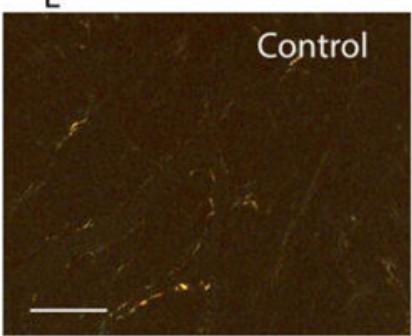

H

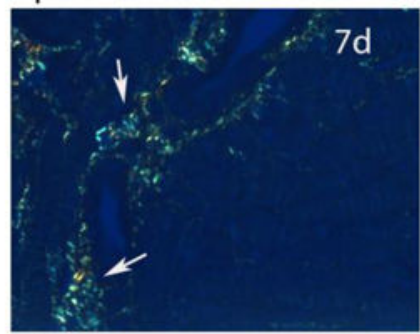

I

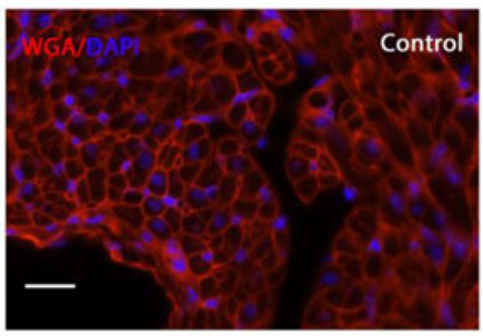

K

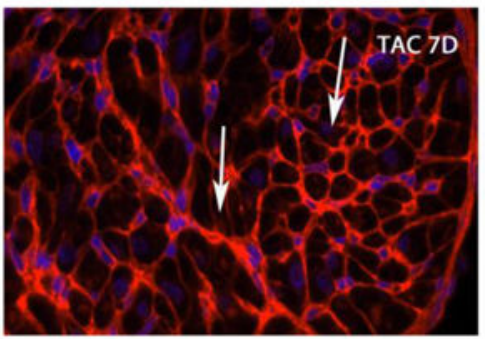

L

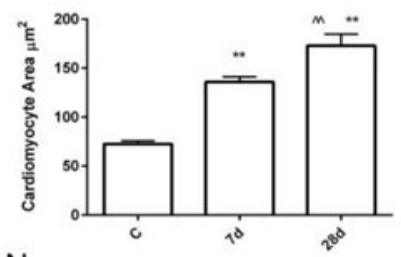

N

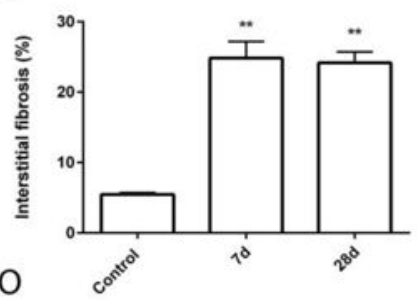

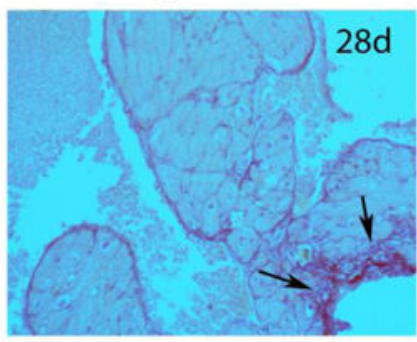

G

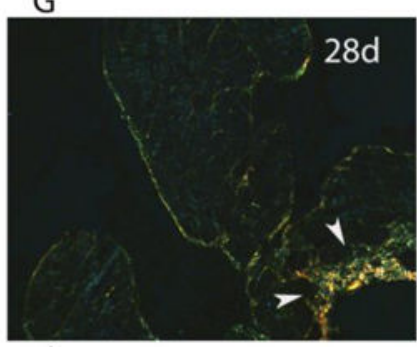

J

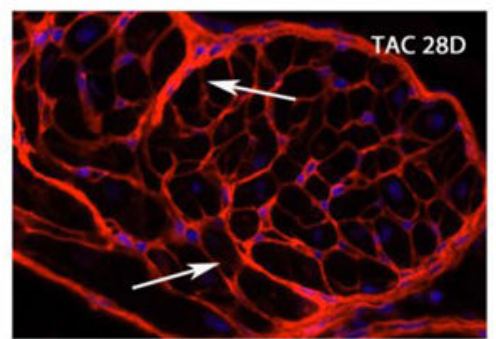

M

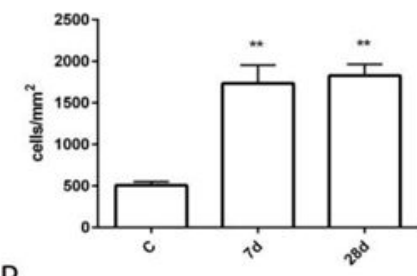

P

Figure 4. Left ventricular pressure overload induces progressive loss of contractile elements in atrial cardiomyocytes and causes atrial cardiomyocyte hypertrophy, and interstitial fibrosis A-D. Hematoxylin-eosin staining shows representative left atrial sections from a control mouse (A) and from pressure-overloaded animals after 7 (B) and 28 days (C-D) of TAC (scalebar $=40 \mu \mathrm{m})$. Pressure-overloaded animals exhibited extensive loss of the myofibrillar component in a subset of atrial cardiomyocytes (arrows). E-J: Sirius red staining visualized with light $(\mathrm{E}-\mathrm{G})$ and polarized microscopy $(\mathrm{H}-\mathrm{J})$ demonstrated significant atrial interstitial fibrosis (arrows) after 7-28 days of TAC. Thicker fibers exhibit orange/red birefringence when visualized with polarized light ( $\mathrm{J}$ - arrowheads). Scalebar $=75 \mu \mathrm{m}$. K-M: WGA lectin 
histochemistry was used to outline cardiomyocytes and to quantitatively assess the atrial interstitial space. DAPI fluorescent staining was used to assess interstitial cellularity. Representative images show WGA/DAPI fluorescence in left atrial sections from control hearts $(\mathrm{K})$ and from pressure-overloaded animals after 7 (L) and $28(\mathrm{M})$ days of TAC $($ scalebar $=25 \mu \mathrm{m})$. N. Quantitative analysis showed that atrial cardiomyocyte size significantly increased after $7-28$ days of TAC $(* * \mathrm{p}<0.01$ vs. control; $* * \mathrm{p}<0.01$ vs. 7 days, $\mathrm{n}=6$ /group). $\mathrm{O}$. The WGA-stained area in the left atrium was significantly increased after 728 days of TAC $(* * \mathrm{p}<0.01$ vs. control, $\mathrm{n}=6 /$ group$)$, suggesting significant atrial interstitial fibrosis. P. Left atrial interstitial cellularity was significantly increased after 7-28 days of TAC $(* * \mathrm{p}<0.01$ vs. control, $\mathrm{n}=6 /$ group $)$. 


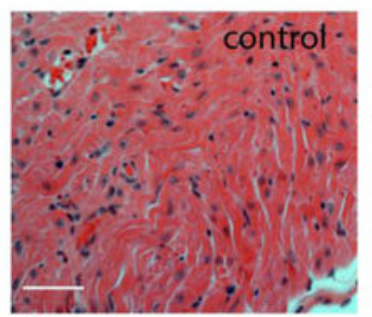

A

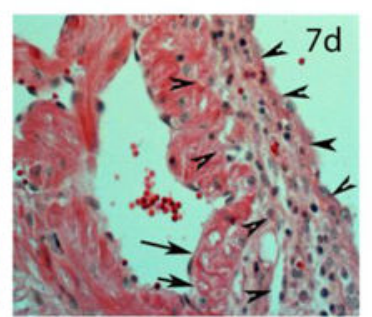

B

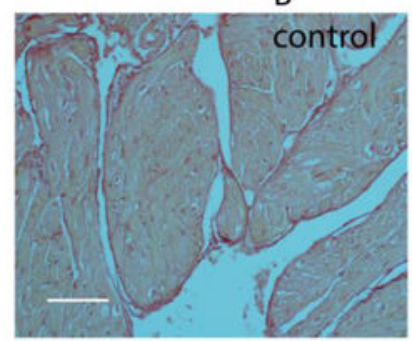

E

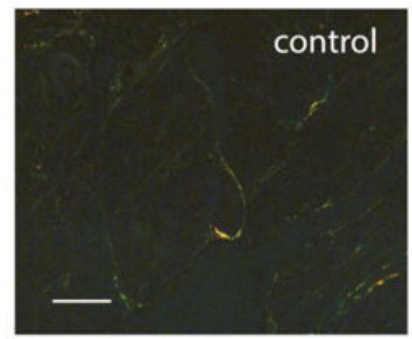

H

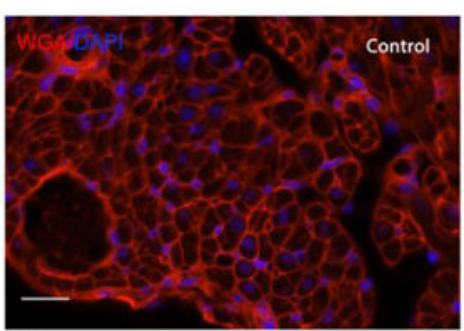

K

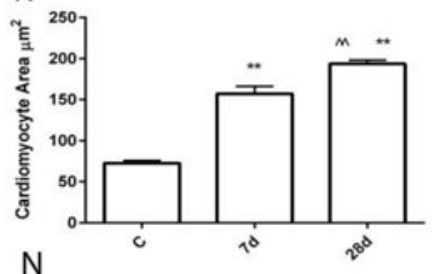

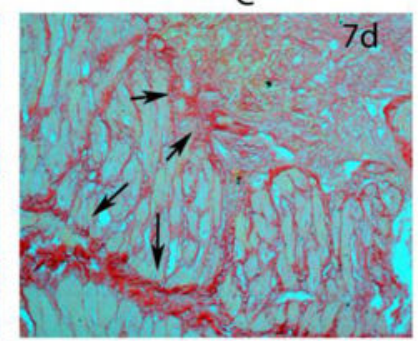

F

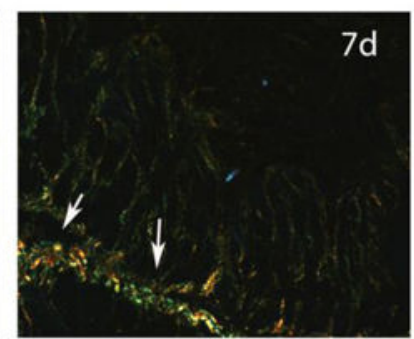

I

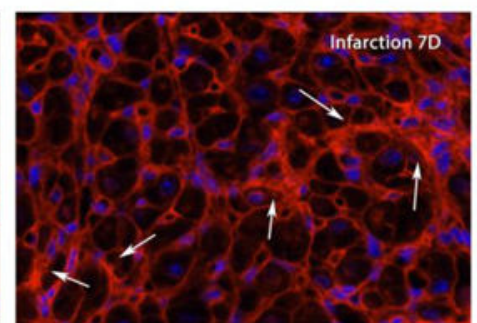

L

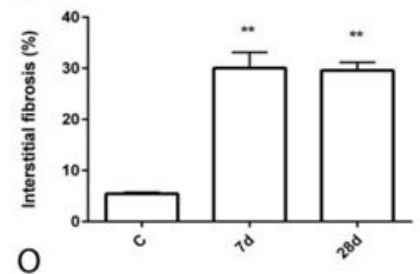

$7 d$
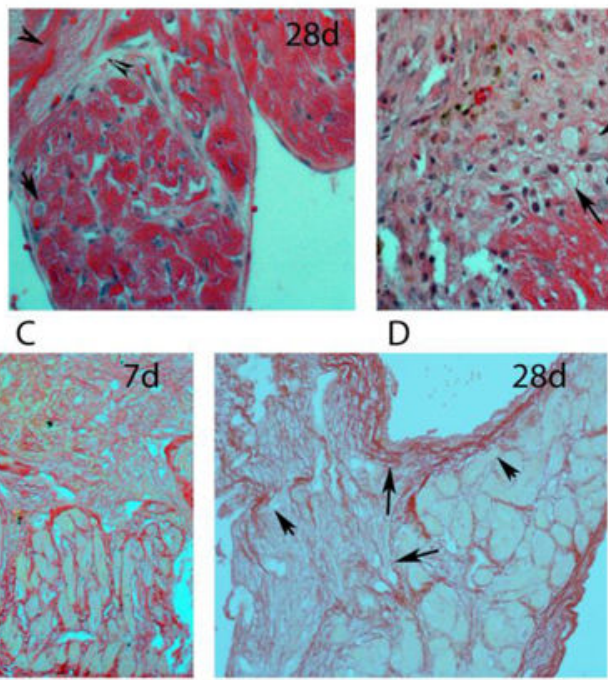

G

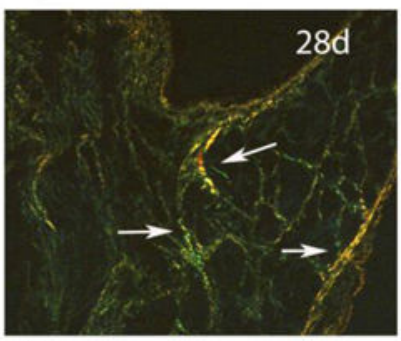

J

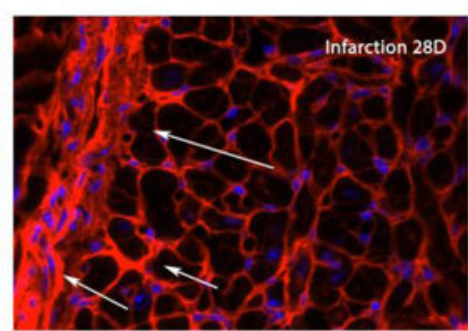

M

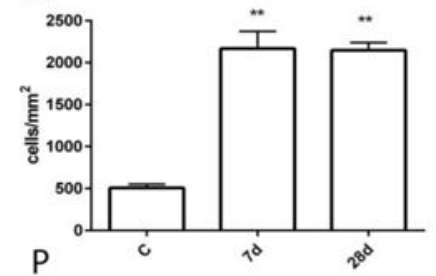

Figure 5. Myocardial infarction is associated with atrial cardiomyocyte hypertrophy and interstitial fibrosis

A-D: Representative hematoxylin-eosin-stained atrial sections from control (A) and infarcted mouse hearts after 7 (B) and 28 days (C-D) of permanent coronary occlusion (scalebar $=40 \mu \mathrm{m}$ ). Infarcted mice showed fibrosis (arrowheads). A significant number of cardiomyocytes exhibited loss of contractile material (arrows). E-J. Sirius red stained sections visualized with light $(\mathrm{E}-\mathrm{G})$, and polarized $(\mathrm{H}-\mathrm{J})$ microscopy show fibrotic remodeling of the atrium following myocardial infarction (arrows, scalebar=60 $\mu \mathrm{m}$ ). Thicker collagen fibers exhibit orange/red birefringence under polarized light (arrows). K-M: WGA/ 
DAPI fluorescence in representative atrial sections from control animals $(\mathrm{K})$ and from infarcted animals after 7 (L) and 28 days of permanent coronary occlusion (M).

Scalebar $=25 \mu \mathrm{m}$. Quantitative analysis showed that left atrial cardiomyocyte size $(\mathrm{N})$, the WGA-stained atrial interstitial area $(\mathrm{O})$, and atrial interstitial cell density $(\mathrm{P})$ were markedly increased 7-28 days after coronary occlusion (**p $<0.01$ vs. control, $* * \mathrm{p}<0.01$ vs. 7 -days, $\mathrm{n}=6$ /group). 


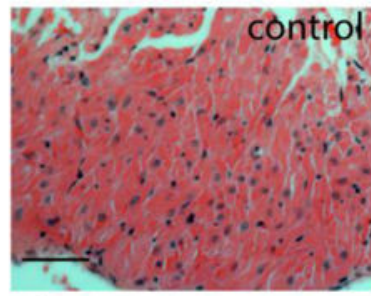

A

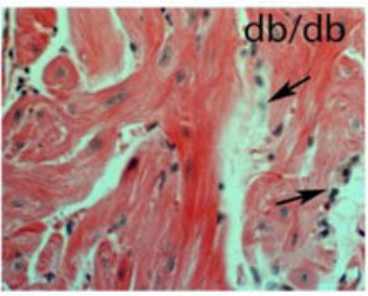

B

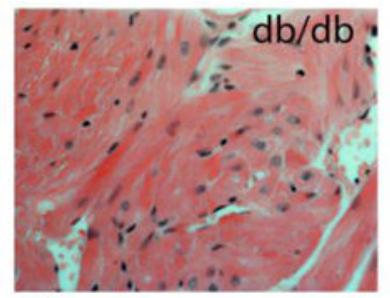

C
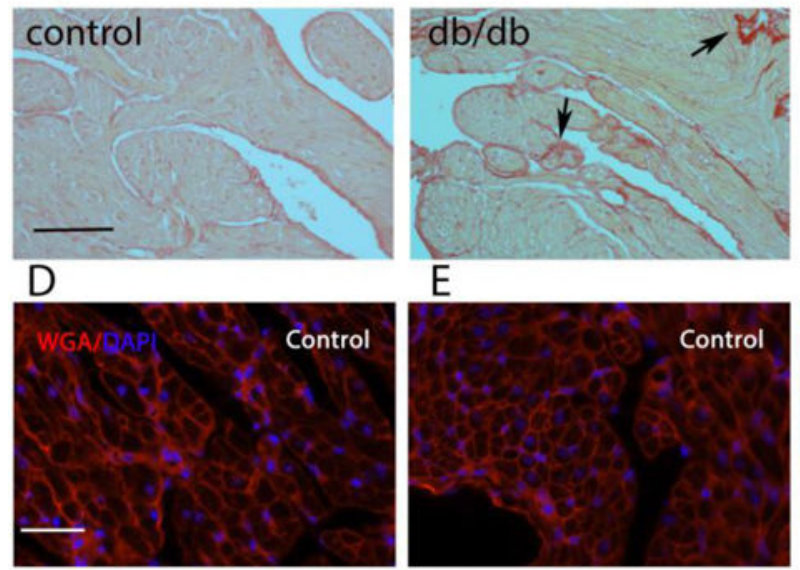

$\mathrm{H}$
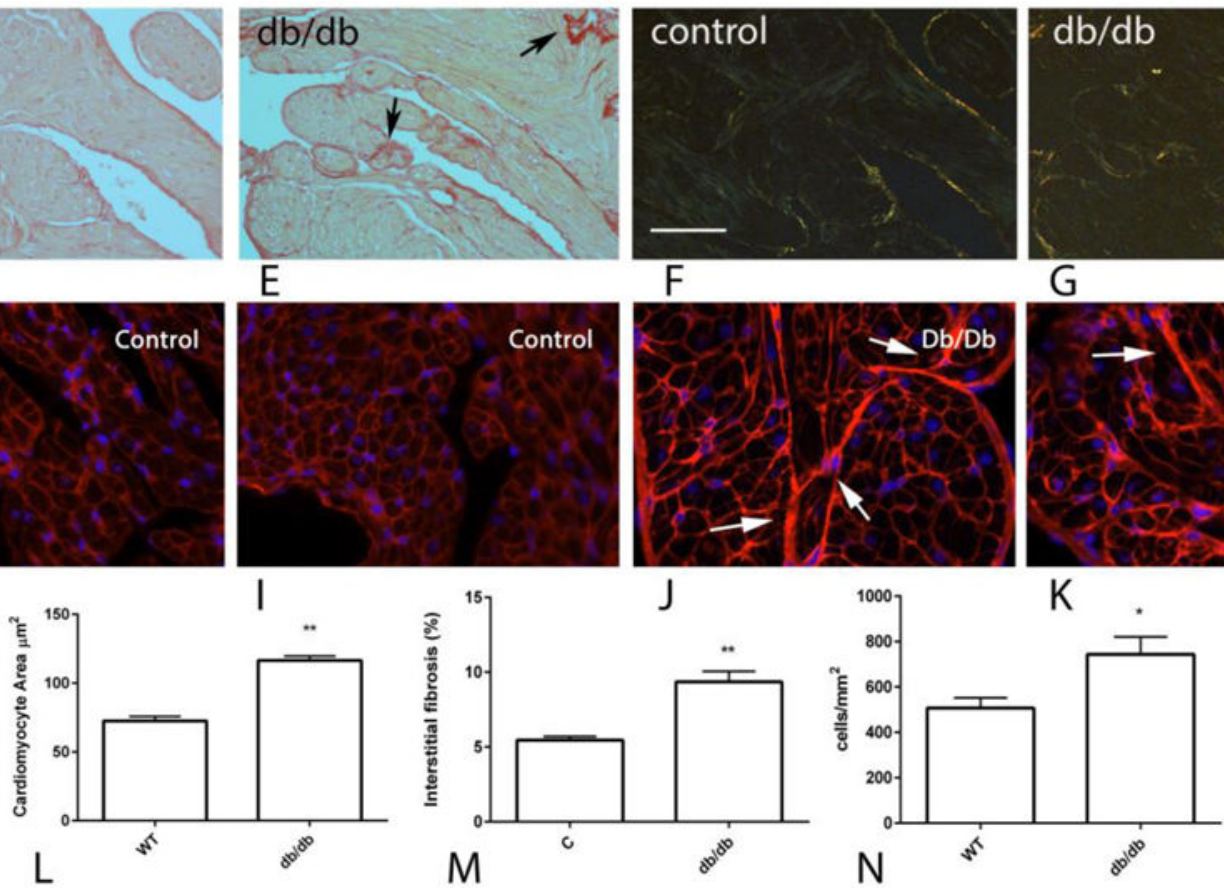

Figure 6. Diabetic hearts exhibit atrial cardiomyocyte hypertrophy and expansion of the atrial interstitium

A-C: Representative hematoxylin-eosin stained left atrial sections show that atria from $\mathrm{db} / \mathrm{db}$ mice have hypertrophic changes and mild fibrosis (arrows) at 6 months of age (scalebar $=40 \mu \mathrm{m}) \mathrm{D}-\mathrm{G}$. Sirius red stained sections visualized with light (D-E), and polarized (F-G) microscopy show mild fibrotic remodeling of the atrium in $\mathrm{db} / \mathrm{db}$ mice (arrows, scalebar $=75 \mu \mathrm{m}$ ). Thicker collagen fibers exhibit orange/red birefringence under polarized light (G, arrow). H-K: Representative images show WGA/DAPI fluorescence in left atrial sections from lean control mice (H, I) and db/db animals (J, K). Scalebar=30 $\mu \mathrm{m} . \mathrm{db} / \mathrm{db}$ animals exhibited increased left atrial cardiomyocyte size (L), an increase in WGA-stained interstitial area $(\mathrm{M})$ and higher interstitial cell density $(\mathrm{N})$ when compared to lean control animals $\left(* \mathrm{p}<0.05,{ }^{* *} \mathrm{p}<0.01\right.$ vs control, $\mathrm{n}=6$ /group $)$. 

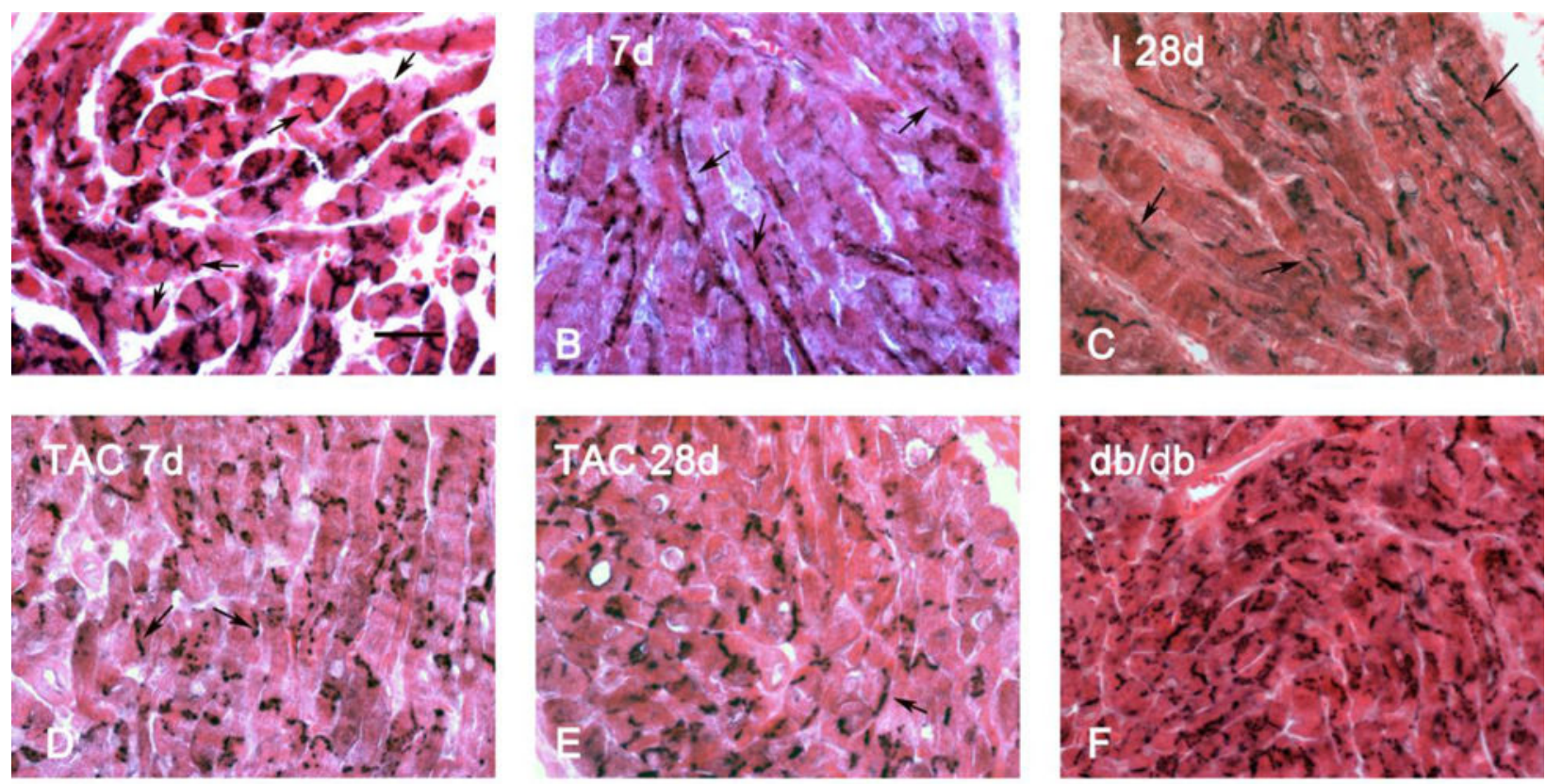

Figure 7. Connexin-43 localization in remodeling atria

A: Immunohistochemical staining shows that in normal mouse left atrium, connexin-43 is localized in intercalated discs (arrows). B-C: Representative left atrial sections from infarcted mice after 7 (B) and 28 days (C) of coronary occlusion show marked reduction of connexin-43 immunoreactivity, associated with loss of the normal pattern and lateralization (arrows). D-E: Attenuated connexin-43 expression and lateralization (arrows) were also noted in pressure overloaded hearts after 7 (D) and 28 days (E) of TAC. F: In contrast, db/db mice did not have significant changes in connexin-43 immunoreactivity. Representative sections show findings from 4 different animals for each group. Scalebar $=25 \mu \mathrm{m}$. 


\section{Table 1}

Left ventricular remodeling in the TAC model of cardiac pressure overload

\begin{tabular}{|l|l|l|l|l|}
\hline & Pre & $\mathbf{7 d}(\mathbf{n = 1 1})$ & Pre & $\mathbf{2 8 d}(\mathbf{n = 8})$ \\
\hline LVEDD $(\mathrm{mm})$ & $3.63 \pm 0.07$ & $3.13 \pm 0.18^{*}$ & $3.01 \pm 0.26$ & $3.86 \pm 0.17^{*}$ \\
\hline Ejection fraction (\%) & $61.32 \pm 3.77$ & $59.08 \pm 7.34$ & $78.54 \pm 3.87$ & $49.89 \pm 4.91^{* *}$ \\
\hline LVEDV (ul) & $55.75 \pm 2.64$ & $40.64 \pm 5.39^{*}$ & $37.87 \pm 7.01$ & $65.62 \pm 7.29^{*}$ \\
\hline AWTd (mm) & $0.90 \pm 0.07$ & $1.37 \pm 0.10^{* *}$ & $0.85 \pm 0.09$ & $1.21 \pm 0.11^{* *}$ \\
\hline PWTd (mm) & $0.70 \pm 0.03$ & $0.96 \pm 0.05^{* *}$ & $0.85 \pm 0.07$ & $0.98 \pm 0.08$ \\
\hline LV mass (mg) & $97.10 \pm 8.30$ & $135.50 \pm 13.71^{*}$ & $84.56 \pm 17.45$ & $161.20 \pm 19.01^{*}$ \\
\hline
\end{tabular}

p $<0.05$,

*** $<0.01$ vs. corresponding baseline. Two distinct groups of animals underwent 7 day $(n=11)$ and 28 day $(n=8)$ TAC protocols. 
Table 2

Left ventricular remodeling in the mouse model of myocardial infarction

\begin{tabular}{|l|l|l|}
\hline & Pre & 28d (n=9) \\
\hline LVEDD (mm) & $3.77+0.10$ & $6.70+0.28^{* *}$ \\
\hline Ejection fraction (\%) & $61.32+3.96$ & $9.81+2.35^{* *}$ \\
\hline LVEDV (ul) & $62.31+4.25$ & $245.20+23.92^{* *}$ \\
\hline AWTd (mm) & $0.74+0.04$ & $0.36+0.05^{* *}$ \\
\hline PWTd (mm) & $0.59+0.02$ & $0.35+0.05^{* *}$ \\
\hline LV mass (mg) & $85.54+7.52$ & $121.10+21.30$ \\
\hline
\end{tabular}

*** $<0.01$ vs. pre 


\section{Table 3}

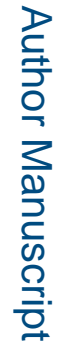

Left ventricular remodeling in diabetic hearts

\begin{tabular}{|l|l|l|}
\hline & Lean $(\mathbf{n}=\mathbf{6})$ & $\mathbf{d b} / \mathbf{d b}(\mathbf{n}=\mathbf{8})$ \\
\hline BW $(\mathrm{gm})$ & $22.81+0.81$ & $59.66+6.42$ \\
\hline TL $(\mathrm{mm})$ & $18.66+0.76$ & $20.25+0.91$ \\
\hline LVEDD $(\mathrm{mm})$ & $3.55+0.21$ & $3.85+0.20$ \\
\hline Ejection fraction $(\%)$ & $67.28+2.71$ & $65.41+1.86$ \\
\hline LVEDV $(\mathrm{ul})$ & $55.98+4.57$ & $73.68+6.73(\mathrm{p}=0.07)$ \\
\hline AWTd $(\mathrm{mm})$ & $0.91+0.01$ & $0.91+0.04$ \\
\hline PWTd $(\mathrm{mm})$ & $0.73+0.04$ & $0.98+0.06^{* *}$ \\
\hline LV mass $(\mathrm{mg})$ & $109.38+13.95$ & $137.27+10.16(\mathrm{p}=0.12)$ \\
\hline E:A & $1.5+0.15$ & $1.54+0.18$ \\
\hline E:E' & $18.6+1.12$ & $37.19+3.72^{* * *}$ \\
\hline
\end{tabular}

*** $<0.01$ vs. lean 
Table 4

Overview of the geometric and histopathological alterations of the left atrium in models of left ventricular disease.

\begin{tabular}{|l|l|l|l|}
\hline Mouse model & Geometric changes & Cardiomyocyte alterations & Interstitial changes \\
\hline Non-reperfused myocardial infarction & $\begin{array}{l}\text { 1. Severe, progressive, } \\
\text { eccentric left atrial } \\
\text { dilation. } \\
\text { 2. Markedly increased left } \\
\text { atrial mass. }\end{array}$ & $\begin{array}{l}\text { 1. Myofibrillar loss in a subset of } \\
\text { cardiomyocytes. } \\
\text { 2. Progressive and severe atrial } \\
\text { cardiomyocyte hypertrophy. } \\
\text { 3. Connexin-43 loss and lateralization. }\end{array}$ & $\begin{array}{l}\text { 1. Severe atrial fibrosis. } \\
\text { with interstitial cells }\end{array}$ \\
\hline Transverse aortic constriction (TAC) & $\begin{array}{l}\text { 1. Severe, progressive } \\
\text { eccentric left atrial } \\
\text { dilation. } \\
\text { 2. Markedly increased left } \\
\text { atrial mass. }\end{array}$ & $\begin{array}{l}\text { 1. Myofibrillar loss in a subset of } \\
\text { cardiomyocytes. } \\
\text { 2. Progressive and severe atrial } \\
\text { cardiomyocyte hypertrophy. } \\
\text { 3. Connexin-43 loss and lateralization. }\end{array}$ & $\begin{array}{l}\text { 1. Severe atrial fibrosis. } \\
\text { 2. Marked infiltration } \\
\text { withterstitial cells }\end{array}$ \\
& $\begin{array}{l}\text { 1. Left atrial dilation. } \\
\text { 2. Increased left atrial } \\
\text { mass. }\end{array}$ & $\begin{array}{l}\text { 1. Atrial cardiomyocyte hypertrophy. } \\
\text { 2. No significant degenerative changes } \\
\text { in atrial cardiomyocytes. } \\
\text { 3. Minimal changes in connexin-43 } \\
\text { localization. }\end{array}$ & $\begin{array}{l}\text { 1. Mild atrial fibrosis. } \\
\text { cell content. }\end{array}$ \\
\hline db/db mouse & & & \\
\hline
\end{tabular}

